Review

\title{
Soluble T Cell Receptor V $\beta$ Domains Engineered for High-Affinity Binding to Staphylococcal or Streptococcal Superantigens
}

\author{
Preeti Sharma, Ningyan Wang and David M. Kranz * \\ Department of Biochemistry, University of Illinois, Urbana, IL 61801, USA; \\ E-Mails: sharma39@illinois.edu (P.S.);ningyan.wang@gmail.com (N.W.) \\ * Author to whom correspondence should be addressed; E-Mail: d-kranz@illinois.edu; \\ Tel.: +1-217-244-2821; Fax: +1-217-244-5858.
}

Received: 16 December 2013; in revised form: 21 January 2014 / Accepted: 22 January 2014 / Published: 28 January 2014

\begin{abstract}
Staphylococcus aureus and group A Streptococcus secrete a collection of toxins called superantigens (SAgs), so-called because they stimulate a large fraction of an individual's $\mathrm{T}$ cells. One consequence of this hyperactivity is massive cytokine release leading to severe tissue inflammation and, in some cases, systemic organ failure and death. The molecular basis of action involves the binding of the SAg to both a T cell receptor (TCR) on a T cell and a class II product of the major histocompatibility complex (MHC) on an antigen presenting cell. This cross-linking leads to aggregation of the TCR complex and signaling. A common feature of SAgs is that they bind with relatively low affinity to the variable region (V) of the beta chain of the TCR. Despite this low affinity binding, SAgs are very potent, as each $\mathrm{T}$ cell requires only a small fraction of their receptors to be bound in order to trigger cytokine release. To develop high-affinity agents that could neutralize the activity of SAgs, and facilitate the development of detection assays, soluble forms of the $\mathrm{V} \beta$ regions have been engineered to affinities that are up to 3 million-fold higher for the SAg. Over the past decade, six different $\mathrm{V} \beta$ regions against SAgs from S. aureus (SEA, SEB, SEC3, TSST-1) or S. pyogenes (SpeA and SpeC) have been engineered for high-affinity using yeast display and directed evolution. Here we review the engineering of these high-affinity $\mathrm{V} \beta$ proteins, structural features of the six different SAgs and the $\mathrm{V} \beta$ proteins, and the specific properties of the engineered $\mathrm{V} \beta$ regions that confer high-affinity and specificity for their SAg ligands.
\end{abstract}


Keywords: superantigens; yeast display; directed evolution; affinity maturation; T-cell receptor; complementarity determining regions; framework regions

\section{Overview}

Over the past 30 years, the family of exotoxins expressed by S. aureus and group A Streptococcus known as "superantigens" (SAgs) [1] has been studied extensively at the molecular and structural levels. There are 24 SAgs known to be expressed by S. aureus, and 11 SAgs known to be expressed by group A Streptococcus [2-5]. Despite their sequence diversity, these toxins exhibit a canonical structural motif that consists of two domains, a smaller N-terminal domain with two $\beta$-sheets and a larger C-terminal domain with a central $\alpha$-helix and a five-stranded $\beta$-sheet [5-8]. This canonical structure has presumably allowed SAgs to maintain their ability to interact with a $\mathrm{T}$ cell receptor V $\beta$ domain on one side of the molecule and a class II product of the MHC on another side [6]. This dual binding is required for activation of $\mathrm{T}$ cells and subsequent cytokine release, as monovalent binding of a ligand to the TCR is not sufficient for signaling. SAg-mediated crosslinking with MHC allows multiple MHC-bound SAg molecules to form a multivalent TCR complex, thereby initiating signaling $[6,9,10]$.

The pathogenic function of SAgs is not clear, although it is likely related to their ability to dysregulate an immune response, or perhaps to generate a cytokine milieu that is favorable for survival of the organism. While the precise functional or evolutionary advantage of expressing a large family of SAgs with extensive sequence diversity is unclear, one clinical consequence has been that antibodies generated against one of the SAgs are not likely to cross-react with most of the other SAgs, thereby limiting the ability of an individual to neutralize multiple toxins [11]. Understanding the clinical correlates of SAg expression are further complicated because of the varied prevalence of individual SAg genes among different bacterial isolates, especially of $S$. aureus [12,13]. Most of the SAgs, including staphyloccocal enterotoxin A (SEA), SEB, SEC, and toxic shock syndrome toxin-1 (TSST-1), are encoded on variable genetic elements [14-17]. Thus, some strains express one or more SAgs while other strains can express a different pattern of SAgs. Finally, there is additional complexity because there is variation in SAg protein expression levels, with some evidence that SAgs SEB, SEC and TSST-1 may be expressed at higher levels than the other SAgs, due to transcriptional regulation [18].

Despite this variability in prevalence and expression levels, it is clear that the potency of SAgs is a direct cause of disease or at the least exacerbates a host of diseases. These include toxic shock syndrome (TSS), pneumonia, purpura fulminans, severe atopic dermatitis, and endocarditis [19-25]. While TSS is the disease most often associated with SAgs, especially TSST-1, the frequency of staphylococcal or streptococcal infections in specific tissues (e.g., lung, skin, soft tissue) results in SAg-mediated, hyper-inflammatory reactions at these sites [26,27]. Specific inhibition of such severe tissue inflammation could be a useful adjunct to treatment of these diseases.

Given the considerable structural information about SAgs and their interaction with $\mathrm{V} \beta$ domains, we embarked over ten years ago on an effort to engineer soluble versions of the V $\beta$ domains against various SAgs for the purpose of developing potent neutralizing agents that could suppress the hyper-inflammatory properties of SAgs [28]. A similar receptor-based strategy has worked for neutralizing the effects of TNF- $\alpha$ with the soluble TNF- $\alpha$ receptor/immunoglobulin fusion 
Etanercept (trade name Enbrel) [29,30]. Because of the low affinity of SAgs for their V $\beta$ receptors, we reasoned that effective neutralization would require the generation of higher affinity variants of the $\mathrm{V} \beta$, which would outcompete toxin engagement by TCRs bearing any V $\beta$ region since the same binding epitope on the SAg is used regardless of the $\mathrm{V} \beta$ region expressed by the $\mathrm{T}$ cell. This affinity maturation has been accomplished using a directed evolution process and yeast display [31,32], an approach that has yielded, to date, high-affinity V $\beta$ proteins against the six SAgs SEA, SEB, SEC3, TSST-1, SpeA, and SpeC [28,33-37]. Several of these have been used successfully in animal models of $S$. aureus infections involving (TSS), pneumonia, skin disease, and endocarditis [20,33,35,36,38]. Here we review features of the entire collection of high-affinity $\mathrm{V} \beta$ domains.

\section{Structural Features of the Superantigens}

SAgs are structurally homologous, even though the primary sequences of the proteins are diverse [1,5]. These proteins are globular and range between 20 and 30 kilodaltons [5]. Although known staphylococcal and streptococcal SAgs have been classified into five groups based on differences in their amino acid sequences [5], here we focus on the six SAgs that have been the targets for high-affinity $V \beta$ regions engineered by yeast display (see below). Sequence alignments of specific members of these groups (TSST-1 from Group I; SEB, SEC3 and SpeA from Group II; SEA from Group III and SpeC from Group IV) are shown in Figure 1. These six SAgs have 10\% to 65\% sequence identity among each other. SEB, SEC3 and SpeA are 50\% to 65\% identical, and perhaps it is not surprising that all three stimulate $T$ cells with the same V $\beta$, mouse V $\beta 8.2$ [5]. Although SpeC belongs to a different group than SEB, SEC3 and SpeA, it exhibits significant sequence homology with these proteins in specific regions, despite having overall low sequence identity (21\% identity with SEB and SEC3, and 24\% identity with SpeA). Overall, TSST-1 is the most distant and contains the lowest level of sequence homology (and $7 \%$ to $20 \%$ identity) to these SAgs.

Examination of the aligned sequences shows that there are several linear stretches of amino acids that are more similar among the six SAgs. Examination of their co-crystal structures with the variable regions of beta chain (V $\beta$ ) of TCRs or with class II MHC ligands suggest that these regions however are among the least homologous (Figure 1). These include residues near the N-terminus centered around position 20 which is part of the epitope for binding the V $\beta$ region of the TCR [39-42]. Other $\mathrm{V} \beta$ binding regions are found between residues 90 to 95 , and near the C-terminus of the protein sequences (positions 215-220), which also appear to lack the same degree of homology as flanking regions which are involved the structural framework for the SAgs. Thus, the residues in these regions, and also their atomic interactions with the cognate $\mathrm{V} \beta$, most often differ and thereby account for the specificity of the interactions between SAg and the TCR. However, it is important to note that SAgs that employ a zinc-dependent binding site for interaction with class II MHC ligands use conserved residues for coordinating zinc ion (Figure 1).

SEA, SEB, SEC3 and SpeA also contain a homologous region (residues 45 to 55 in Figure 1) that serves as a binding site for class II MHC [43-47]. These same four SAgs, but not SpeC and TSST-1, possess a characteristic cystine loop of 9 to 19 residues [48,49], which has been implicated in emetic activity of SAgs. Toxins such as SpeC and TSST-1 that lack the cystine loop have been shown to exhibit reduced to no emetic activity [50]. 
Figure 1. Sequence alignment of various superantigen sequences. The sequence of each superantigen (SAg) was obtained from the PDB file corresponding to its crystal structure. Multiple sequence alignment [CLUSTAL W (1.81)] was performed using "Biology WorkBench" online tool. Positions with homologous amino acids in three or more SAg sequences are highlighted in yellow or green. Residues in red are involved in forming the characteristic disulfide loop in certain SAg. Residues underlined in red and in blue are involved in binding to V $\beta$ and class II MHC, respectively. Residues in bold are involved in binding zinc.

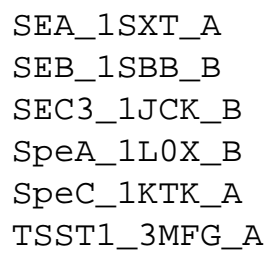

SEA_1SXT_A SEB_1SBB_B SEC3_1JCK_B SpeA_1LoX_B SpeC_1KTK_A TSST1_3MFG_A

SEA_1SXT_A SEB_1SBB_B SEC3_1JCK_B SpeA_1LOX_B SpeC_1KTK_A TSST1_3MFG_A

SEA_1SXT_A SEB_1SBB_B SEC3_1JCK_B SpeA_1LoX_B SpeC_1KTK_A

10

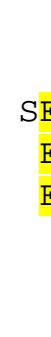

SEKSEEINEKDLRKKSELQGTALGNLKQIYYYNEKAKTENKESHDQFLQ ESQPDPKPDELHKSSKFTGLMEN- - MKVLYDDNHVSAINVKSIDQFLYFDLIYSIKDTK ESQPDPMPDDLHKSSEFTGTMGN - MKYLYDDHYVSATKVKSVDKFLAHDLIYNINDKK

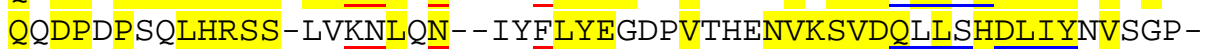
DSKKDISNVKSDLLYAYTITP - - - - - - YDYKDCRVNFSTTHTLNIDTQKYRGKD - -

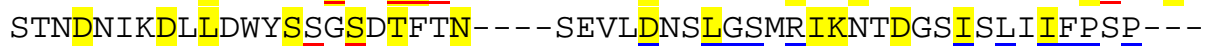

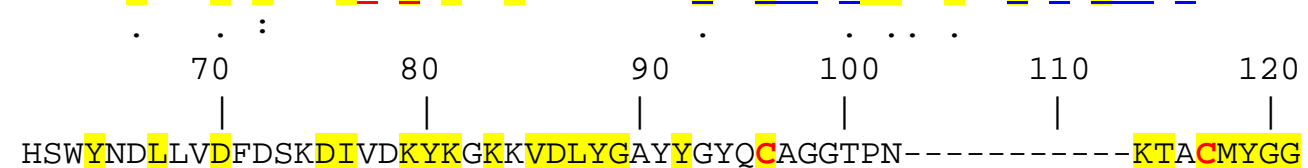

LGNYDNVRVEFKNKDLADKYKDKYVDVFGANYYYOCYFSKKTNDINSHQTDKRKT - CMYGG LNNYYDKVKTELLNEDLANKYKDEVVDVYGSNYYVNCY'FSSKD - - - NVGKVTSGKT - CMYGG

- - NYPKLKTELKNQEMATLFKDKNVDIYGVEYYHLCYLSEN - - - - - - - AERSA - CIYGG

- - -YYYISSEMSYEASQKFKRDDHVDVFGLFYILNSHTG - . . . . . . - . - EYIYGG

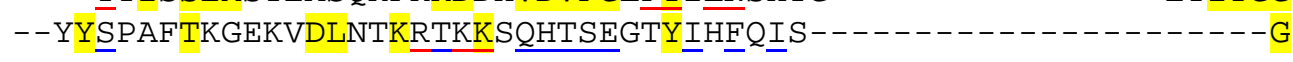<smiles>C[As](C)O[Ga][Te]</smiles>

VTLHDNNRLTEEKKVPINLWLDGKQNTVPLETVKTNKKNVTVQELDLQARRYLQEKYNLY VTEHNGNQLD - KYRSITVRVFEDGKNLLSFDVQTNKKKVTAQELDYLTRHYLVKNKKLY ITKHEGNHFDNGNLQNVLIRVYENKRNTISFEVQTDKKSVTAQELDIKARNFLINKKNLY VTNHEGNHLE - - IPKKIVVKVSIDGIQSLSFDIETNKKMVTAQELDYKVRKYLTDNKQLY ITPAQNNKVN - - HKLLGNLFISGESQQNLNNKI ILEKDIVTFQEIDFKIRKYLMDNYKIY VTNTEKLPTP - - IELPLKVKVHGKD - SPLKYYWPKFDKKQLAISTLDFEIRHQLLTQIHGLY $:^{*}: \quad: \quad:$ : $:{ }^{*}:::^{*}{ }^{*} .{ }^{*} .:^{*}$ \begin{tabular}{ccccc|}
190 & 200 & 210 & 220 & 230
\end{tabular} EFNNSP - - YETGYIKFIE - NENSFWYDMMPAPGDKFDQSKYLMMYNDNKMVDSK - DVKIE EFNSSP - -YETGYIKFIESNGNTFWYDMMPAPGDKFDQSKYLMIYKDNKMVDSK - SVKIE TNNGPSK - - YETGYIKFIPKNKESFWFDFFPEP - - EFTQSKYLMIYKDNETLDSN - TSQIE DATSP - - YVSGRIEIGTKDGKHEQIDLFDSPN - EGTRSDIFAKYKDNRI INMKNFSHFD RSSDKT - - - - GGYWWITMNDGSTYQSDLS - - - - - - - - KKFEYNTEKPPINIDEIKTIE 246

IYLYTS VYLTTKKK VHLTTKNG VYLTTK IYLL-EK

\section{Consensus key:}

* - single, fully conserved residue

: - conservation of strong groups

- conservation of weak groups - no consensus

Although many of the staphylococcal and streptococcal SAgs possess overall low sequence identity, their structures possess striking similarity. The canonical structure consists of a N-terminal, $\beta$-barrel 
containing domain and a C-terminal domain containing a $\beta$-grasp motif and an $\alpha$-helix which spans the center of the structure, connecting the two domains [5] (Figure 2). In the past two decades, a number of crystal structures of SAg have been solved (Table 1, only those that are relevant to this review are shown). Co-crystal structures with the $\mathrm{V} \beta$ region of TCR or class II MHC, have provided the basis for understanding SAg interactions with receptors on $\mathrm{T}$ cells and antigen presenting cells. The different modes of interaction of each SAg with these receptors reveal the diversity in mechanisms of binding to $\mathrm{V} \beta$ and MHC-II, which is particularly intriguing considering they possess highly conserved three-dimensional folds.

Four different modes of interaction of SAgs with class II MHC have been described: (1) SEB, SEC, SpeA bind to class II MHC alpha chain with a single, low affinity binding site that is located in the $\mathrm{N}$-terminal domain of the protein. This binding is independent of the peptide located in the groove of the MHC-II molecule; (2) TSST-1 on the other hand uses a peptide-dependent binding mechanism to interact with low affinity to the class II MHC alpha chain through the TSST- 1 N-terminal binding domain; (3) SpeC binds to the beta chain of class II MHC with high affinity, in a zinc-dependent manner through the C-terminal domain of SpeC; (4) SEA contains both a low affinity binding site and a high affinity, zinc-dependent site which could possible involve cross-linking of MHC molecules [43-45,47,51,52]. Structural features of SAg binding to the V $\beta$ domains are described below.

Figure 2. Two-domain architecture of superantigens. The canonical structure of SAg consists of two domains. The N-terminal domain (red) consists of a $\beta$ barrel motif and C-terminal domain (blue) consists of a $\beta$-grasp motif and an $\alpha$-helix which spans the center of the structure.

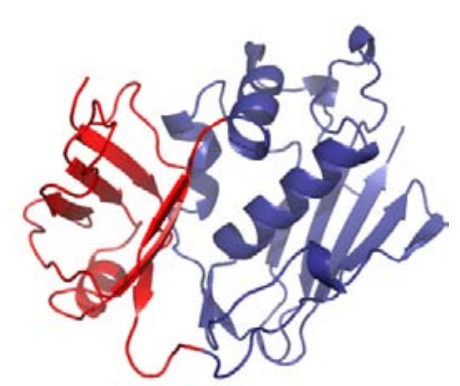

SEA

PDB: 1SXT

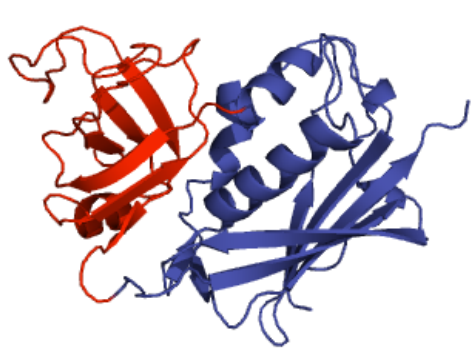

SEB

PDB: 1SBB

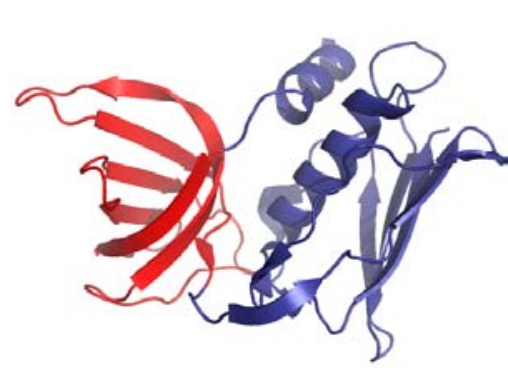

TSST-1

PDB: 3MFG

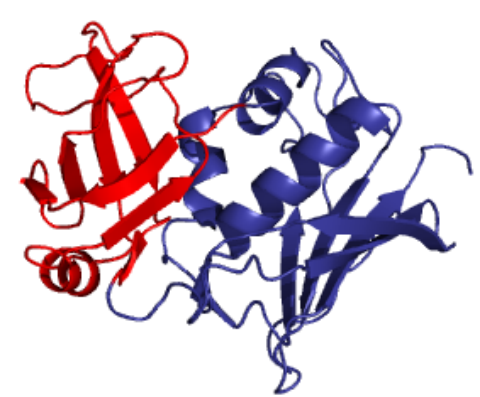

SEC3

PDB: 1JCK

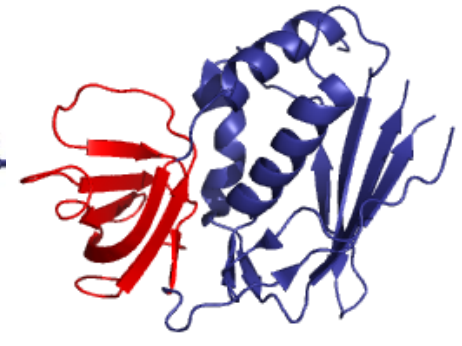

SpeC

PDB: 1KTK

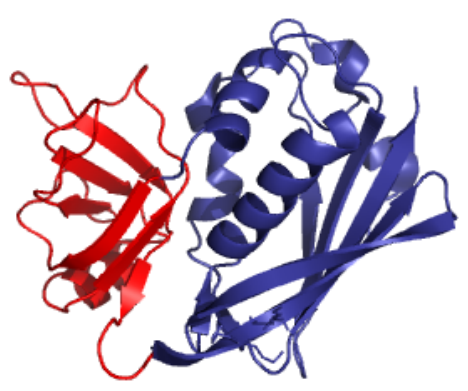

SpeA

PDB: 1LOX 
Table 1. Crystal structures of staphylococcal and streptococcal superantigens and their complexes with $\mathrm{V} \beta$ domains.

\begin{tabular}{|c|c|c|c|c|}
\hline Organism & SAg & Crystal Structure (PDB code, ligand) & Year & Reference \\
\hline S. aureus & \multirow{2}{*}{ SEA } & 1ESF (co-crystallized with $\mathrm{Cd}^{2+}$ ) & 1995 & [53] \\
\hline S. aureus & & 1SXT (co-crystallized with $\mathrm{Zn}^{2+}$ ) & 1996 & [54] \\
\hline S. aureus & \multirow{3}{*}{ SEB } & 3SEB & 1998 & {$[55]$} \\
\hline S. aureus & & 1SBB (co-crystallized with $\mathrm{mV} \beta 8.2$ ) & 1998 & [39] \\
\hline S. aureus & & $\begin{array}{l}\text { 3R8B (co-crystallized with affinity matured } \mathrm{mV} \beta 8.2 \\
\text { mutant G5-8) }\end{array}$ & 2011 & {$[56]$} \\
\hline S. aureus & \multirow{3}{*}{ SEC3 } & 1CK1 (co-crystallized with $\mathrm{Zn}^{2+}$ ) & 2002 & [57] \\
\hline S. aureus & & 1JCK (co-crystallized with mV $\beta 8.2$ ) & 1996 & [40] \\
\hline S. aureus & & $\begin{array}{l}\text { 2AQ3 (co-crystallized with affinity matured mV } \beta 8.2 \\
\text { mutant L2CM) }\end{array}$ & 2005 & {$[58]$} \\
\hline S. aureus & \multirow{3}{*}{ TSST1 } & 2QIL & 1996 & [59] \\
\hline S. aureus & & $\begin{array}{l}\text { 2IJ0 (co-crystallized with affinity matured hV } \beta 2.1 \\
\text { mutant D10) }\end{array}$ & 2007 & {$[42]$} \\
\hline S. aureus & & $\begin{array}{c}\text { 3MFG (co-crystallized with hV } \beta 2.1 \text { stabilized } \\
\text { wild-type EP-8) }\end{array}$ & 2011 & {$[56]$} \\
\hline S. pyogenes & \multirow[t]{2}{*}{ SpeA } & $\begin{array}{l}\text { 1FNU (co-crystallized with } \mathrm{Cd}^{2+} \text { ) } \\
\text { 1FNV (co-crystallized with } \mathrm{Cd}^{2+} \text { ) } \\
\text { 1FNW (co-crystallized with } \mathrm{Cd}^{2+} \text { ) }\end{array}$ & 2000 & {$[60]$} \\
\hline S. pyogenes & & $\begin{array}{l}\text { 1L0X (co-crystallized with } \mathrm{mV} \beta 8.2 \text { ) } \\
\text { 1L0Y (co-crystallized with } \mathrm{mV} \beta 8.2 \text { and } \mathrm{Zn}^{2+} \text { ) }\end{array}$ & 2002 & {$[41]$} \\
\hline S. pyogenes & \multirow{2}{*}{ SpeC } & 1AN8 & 1997 & {$[61]$} \\
\hline S. pyogenes & & 1KTK (co-crystallized with hV $\beta 2.1$ ) & 2002 & [41] \\
\hline
\end{tabular}

\section{Engineering High-Affinity T Cell Receptor V $\beta$ Domains against Superantigens SEA, SEB, SEC3, TSST-1, SpeA, and SpeC}

Except for staphylococcal enterotoxin $\mathrm{H}$ (SEH), which has been shown to interact primarily with the variable region of alpha chain of the TCR [62,63], most SAgs are known to specifically interact with variable regions of TCR beta chain. The hallmark feature of SAgs is that they stimulate T-cells that bear a specific subset of variable regions in their beta chains (V $\beta$ ) [64,65]. Interestingly, despite their potent activity, SAgs are known to bind to their cognate $\mathrm{V} \beta$ receptors with low affinity $\left(\mathrm{K}_{\mathrm{D}}\right.$ values in the micromolar range) (Table 2 and [66-68]). In order to develop an antagonist that can effectively neutralize their toxic effects in vivo, a panel of six soluble, high-affinity TCR V $\beta$ mutants have been engineered [28,33-37]. These V $\beta$ mutants bind to one of six key staphylococcal and streptococcal SAgs (SEA, SEB, SEC3, TSST1, SpeA, and SpeC), at the same epitope as the wild type receptors but with much higher affinity, in the picomolar to nanomolar range. These represent 1000 to 3,000,000-fold increases in affinity, compared to wild-type (Table 2). Unlike antibodies, which could bind to any epitope of the SAg, engineering of the V $\beta$ ensures that the neutralizing agent binds the identical SAg epitope as the wild-type receptor, thereby ensuring that direct competition and corresponding neutralization occurs. 
Table 2. High-affinity V $\beta$ domains that bind to various superantigens.

\begin{tabular}{|c|c|c|c|c|c|c|c|}
\hline \multirow{2}{*}{ Organism } & \multirow{2}{*}{ SAg } & \multicolumn{2}{|c|}{ WT V $\beta$} & \multicolumn{2}{|c|}{ High affinity V $\beta$} & \multirow{2}{*}{$\begin{array}{c}\text { Improvement in } \\
\text { affinity (fold) }\end{array}$} & \multirow{2}{*}{ References } \\
\hline & & Name & Affinity $(\boldsymbol{\mu M})$ & Name & Affinity (pM) & & \\
\hline S. aureus & SEA & Human V $\beta 22$ & 100 & FL & 4,000 & 25,000 & [37] \\
\hline S. aureus & SEB & Mouse V $\beta 8.2$ & 144 & G5-8 & 50 & $2,880,000$ & {$[33,66]$} \\
\hline S. aureus & SEC3 & Mouse V $\beta 8.2$ & 3 & L3 & 3,000 & 1,000 & {$[36,66]$} \\
\hline S. aureus & TSST1 & Human V $\beta 2.1$ & 2.3 & D10 & 180 & 13,000 & [34] \\
\hline S. pyogenes & SpeA & Mouse V $\beta 8.2$ & 6 & KKR & 270 & 22,000 & {$[35,66]$} \\
\hline S. pyogenes & SpeC & Human V $\beta 2.1$ & 20 & HG_FI & 500 & 40,000 & {$[41,69]$} \\
\hline
\end{tabular}

All high-affinity V $\beta$ mutants were engineered using yeast display technology (Figure 3) [31,32] and directed evolution. The process involved use of a wild type V $\beta$ from TCRs known to be stimulated by the SAg of interest. This $V \beta$ gene was cloned into the yeast display vector in frame with the yeast mating protein, Aga2 to be displayed on the yeast surface. The $\mathrm{V} \beta$ gene was flanked by hemagglutinin (HA) and c-myc tags, which served as probes of the protein expression. Unlike many antibody variable domains, wild type $\mathrm{V} \beta$ domains typically require that one or more key mutations be engineered into the protein in order to be expressed on the yeast cell surface [70,71]. To accomplish this, the V $\beta$ gene was subjected to error prone PCR to introduce random mutations, and the library was selected by fluorescence-activated cell sorting (FACS) with a conformation-specific anti-V $\beta$ antibody (these are typically available commercially against most of the human $\mathrm{V} \beta$ regions). Anti-V $\beta$ antibody is used, rather than fluorophore-labeled SAg at this stage, as the affinity of the SAgs with wild type V $\beta$ are so low that detection by flow cytometry is not possible. The mutated V $\beta$ region that allows it to be expressed on the surface of yeast is often called a stabilized $\mathrm{V} \beta$ as it has been shown that such mutations yield stabilized, soluble domains [72] (Figure 4).

Figure 3. Schematic of yeast display system for engineering high-affinity V $\beta$ domains against Superantigens. The V $\beta$ libraries with various mutations are fused to the $\mathrm{C}$ terminus of the yeast mating protein Aga-2 to be displayed on the yeast cell surface. HA and c-myc tags are included in the fusion gene to probe and quantify the $\mathrm{V} \beta$ protein expression level. Fluorescent ligands include either a monoclonal antibody to the V $\beta$ region or the SAg.

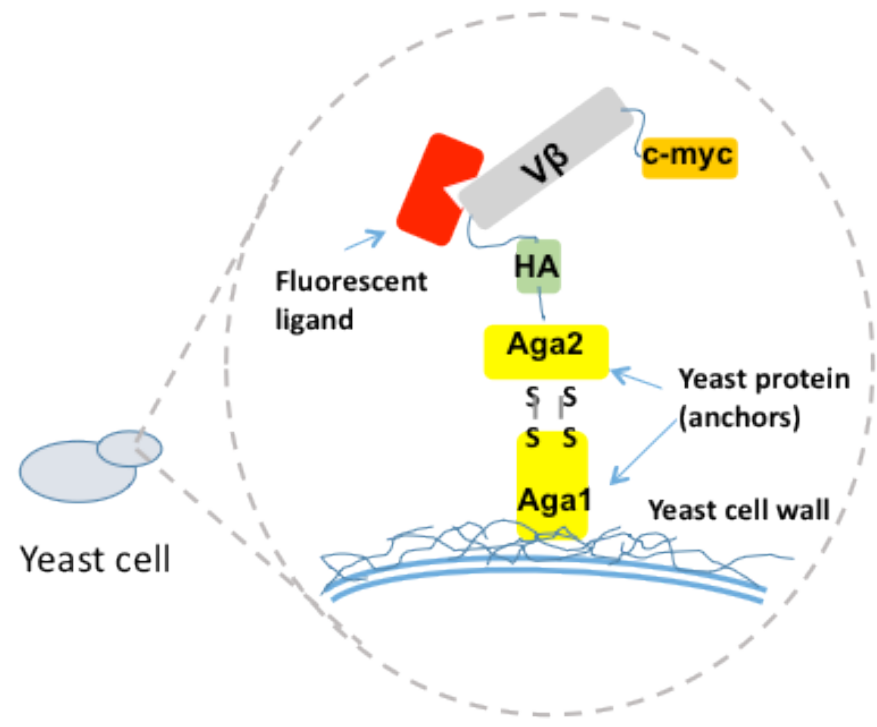


Stabilized V $\beta$ region genes served as templates for either additional random mutagenesis or for site-directed mutagenesis to generate libraries (Figure 4) with mutations in the putative SAg-binding sites. Typically, selection of the sites for mutagenesis was guided by the crystal structure of V $\beta: \mathrm{SAg}$ complexes. If structural information was not available, such as with the recent engineering of $\mathrm{V} \beta$ against SEA [37], the residues in CDR2 were chosen to generate the first generation site-directed mutagenesis libraries because of its central role in the interaction of other V $\beta$ regions with SAgs, as observed in V $\beta:$ SAg crystal structures [39-42]. To construct the site-directed mutagenesis libraries, amino acid positions were encoded by randomized codons (NNS) in primers, and cloned by PCR using overlapping primers. PCR products were transformed into yeast cells by homologous recombination, yielding library sizes of $10^{6}-10^{8}$ transformants.

Figure 4. General flow chart for the cloning, display and engineering of high-affinity V $\beta$ neutralizing agents by yeast display. A V $\beta$ clone that is specific for the SAg of interest is cloned into the yeast display vector (Figure 3) and used to generate libraries of mutants. The libraries are selected with fluorescently-labeled ligands, (e.g., conformation-specific anti-V $\beta$ antibodies or the SAg of interest). Multiple rounds of selections are conducted to enrich the V $\beta$ mutants with desired properties, which serve as templates for subsequent library design and screening to achieve desirable stability or affinity of V $\beta$ with SAg.

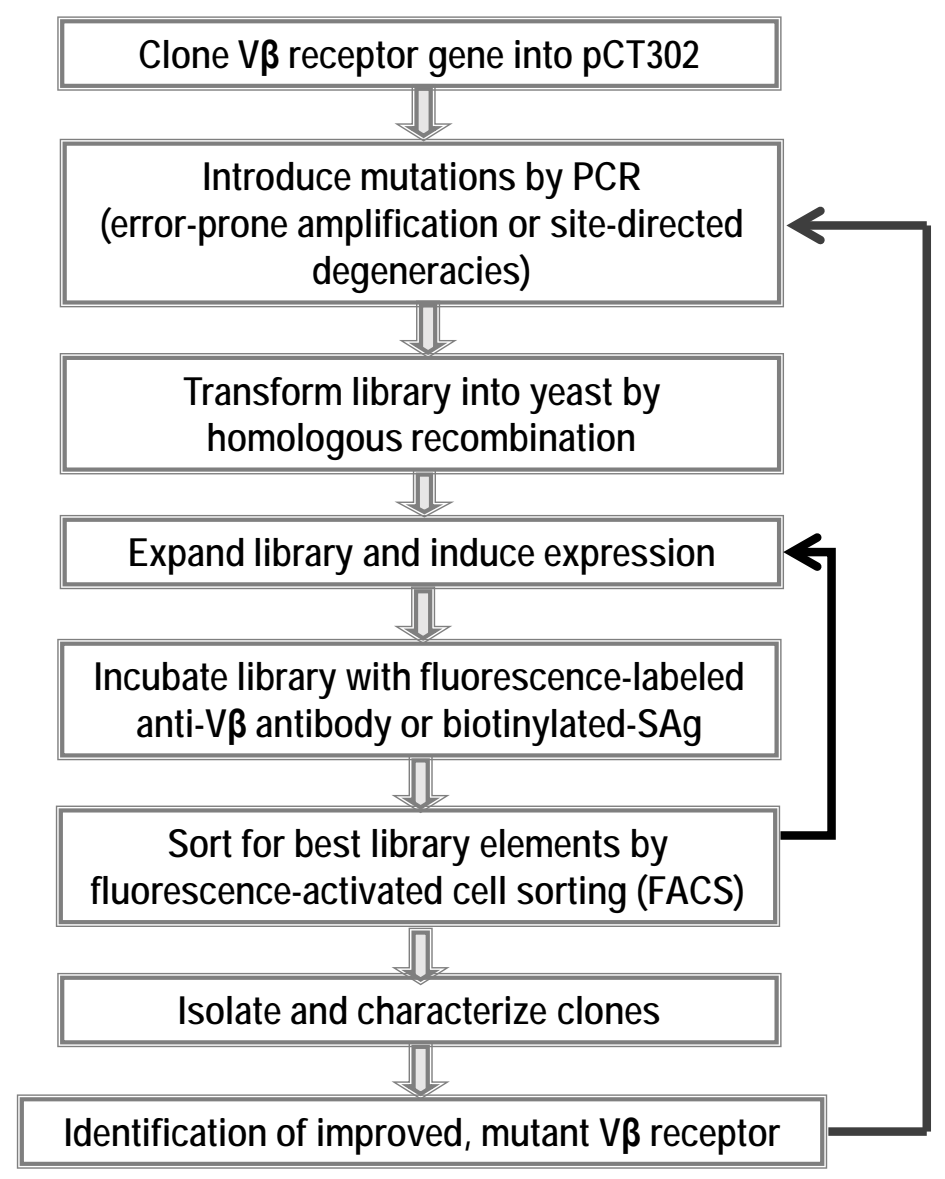

Pre-selected degenerate libraries typically exhibit no detectable binding with SAg by flow cytometry due to their low affinity, or loss of binding, by the great majority of mutants. To select for the rare V $\beta$ mutants that exhibit higher affinity binding, libraries were subjected to several rounds of selection with a 
decreasing concentration of biotinylated-SAg, followed by staining with fluorescently-labeled streptavidin, and fluorescence-activated cell sorting (FACS). In each round of selection, a small fraction of cells that exhibited the top 1\% fluorescence upon selection with SAg of interest, were collected and expanded for subsequent rounds of screening. When a distinct yeast population with positive SAg-staining emerged after 3 4 rounds of selection, yeast cells were plated and higher affinity clones were isolated, characterized and sequenced. In the recent engineering of V $\beta 22$ against SEA, mutations isolated from the CDR2 library alone were capable of increasing the SEA affinity by 25,000-fold [37]. Even more strikingly, with the engineering of mouse V $\beta 8.2$ against SEB, mutations from one CDR2 library accounted for a 220,000-fold increase of V $\beta$ affinity with SEB (from $144 \mu \mathrm{M}$ wide type affinity to $650 \mathrm{pM}$ for G2-5) [33]. These results further validated the essential role of CDR2 loop in V $\beta$ :SAg interactions (see below).

Following the initial selection, additional mutagenized libraries were often constructed in regions (CDR1, HV4 and FR3) that flank the CDR2 tertiary structure, using one or a combination of the first generation lead mutants as templates. After further affinity- or off-rate-based selections, mutants exhibited a more modest 10 to 100 fold further increase in affinity. The specific region(s) where higher affinity mutations were successfully isolated for each pair of V $\beta / \mathrm{SAg}$ reflected, in part, the diverse binding modes of the SAgs with their cognate V $\beta$ s. Ultimately, mutations isolated from multiple libraries could be combined to generate the highest affinity mutants that yielded 1000 to 3,000,000-fold increases in affinity with targeted SAgs compared to the wild type V $\beta$.

\section{Topology of V $\beta$ :Superantigen Interactions}

Crystal structures of five out of six SAgs discussed in this review have been solved in complex with their cognate $\mathrm{V} \beta$ receptor ligand (Figure 5B-F) [39-42]. In general, the $\mathrm{V} \beta$ receptor docks in the cleft between the two domains of the SAg and uses its hypervariable loops (CDRs), or specific framework regions for engagement (Figure 5). Co-crystal structures of different SAg with their cognate V $\beta$ ligands indicate that $\mathrm{V} \beta$ domains interact with the SAgs with considerable diversity in positioning and in interaction chemistries. However, the CDR2 loop of V $\beta$ appears to be central to each SAg-TCR interaction [73,74] (Figure 5). Other regions of the $\mathrm{V} \beta$ appear to play important, but supporting roles, in the binding energy and specificity for the SAg [34,73,75].

SEB, SEC3 and SpeA (Group II SAg) are more structurally similar and each has been co-crystallized with murine $\mathrm{V} \beta 8.2$ (mVß8.2) [39-41]. As indicated, these three SAgs possess $50 \%-65 \%$ sequence identity and they engage with the V $\beta 8.2$ region of the TCR using similar residues (Figure 1), thereby determining their specificity for mV $\beta 8.2$. Accordingly, SEB, SEC3 and SpeA interact with mVB8.2 with similar topologies (Figure 5), and they engage in intermolecular contacts primarily with CDR2 (accounting for 50\%, 63\% and 33\% of total contacts respectively), HV4 and to some extent framework (FR) regions.

The mechanisms by which these three SAgs interact with $\mathrm{mV} \beta 8.2$ are largely dependent on the common conformation of CDR2 and HV4, although SpeA forms a distinct contact via its E94 residue, by forming hydrogen bonds with N28 of CDR1 loop of mV $\beta 8.2$ [41]. Since SEB and SEC3 depend primarily on interactions with main chain atoms of $\mathrm{V} \beta$-CDR2, their $\mathrm{V} \beta$ binding specificity is considerably reduced. However, SpeA:V $\beta 8.2$ interaction specificity appears to be enhanced because the interface involves $\mathrm{H}$-bonds between side chain atoms from both SpeA and the V $\beta$ molecule. 
Figure 5. Co-crystal structures of six superantigens with cognate V $\beta$ domain of the $T$ cell receptor. Except for SEA, the co-crystal structures of SAg (blue) with their cognate V $\beta$ ligand (gray) are available in PDB (Table 1). Residues of SAg interacting with V $\beta$ are indicated in teal. Various regions of $\mathrm{V} \beta$ are colored as follows: CDR1 (green); CDR2 (Red); CDR3 (orange); HV4 (purple); FR2 (olive) and FR3 (yellow). Interacting residues of $\mathrm{V} \beta$ and SAg are displayed in stick configurations. (A) The SEA crystal structure was manually docked with mouse V $\beta 16$ crystal structure (PDB: 4ELK), that is $66 \%$ identical to human V $\beta 22$ protein sequence; (B) Co-crystal structure of TSST-1 with human V $\beta 2.1$ mutant, EP-8; (C) Co-crystal structure of SpeC with human Vß2.1; (D) Co-crystal structure of SEB with mouse V $\beta 8.2$; (E) Co-crystal structure of SEC3 with mouse V $\beta 8.2$; (F) Co-crystal structure of SpeA with mouse V $\beta 8.2$.

A

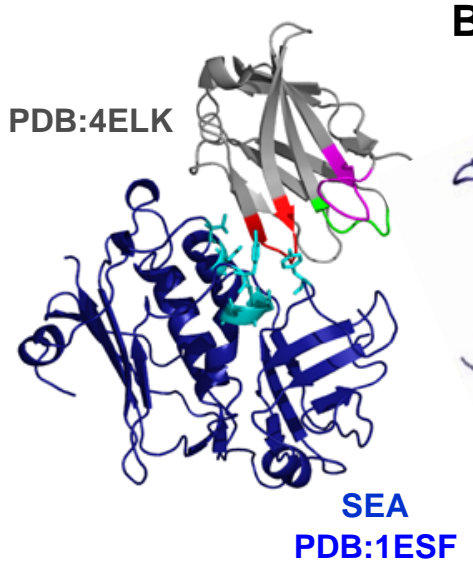

PDB:1ESF

D

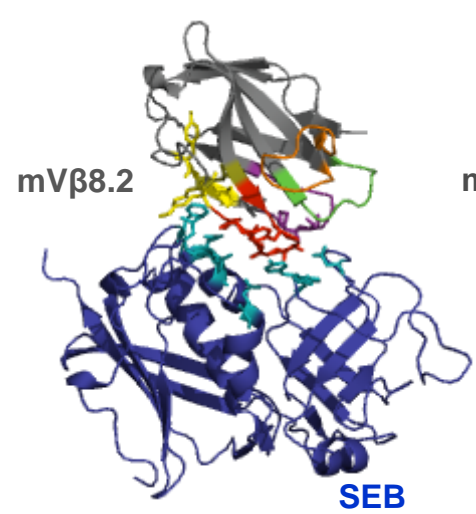

PDB: 1SBB
B

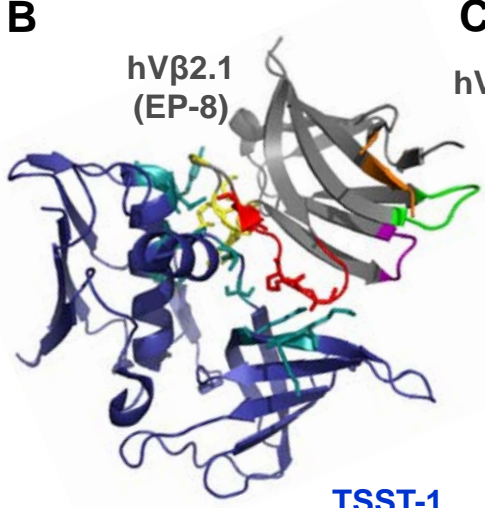

PDB:3MFG

E

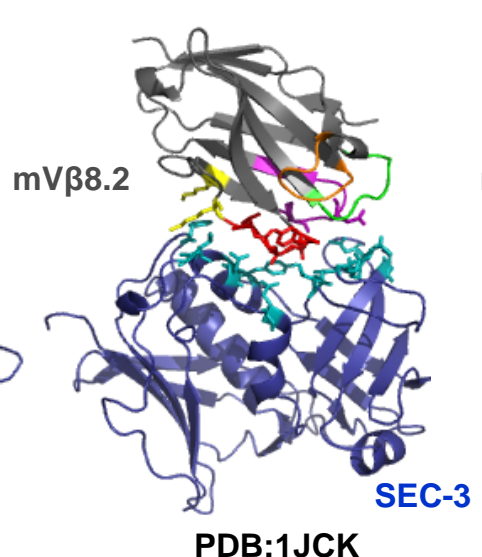

C hVß2.1

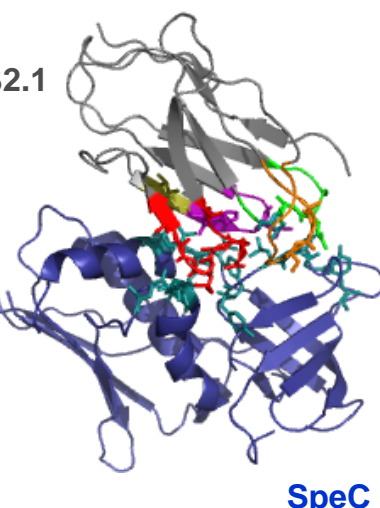

PDB:1KTK

$\mathbf{F}$

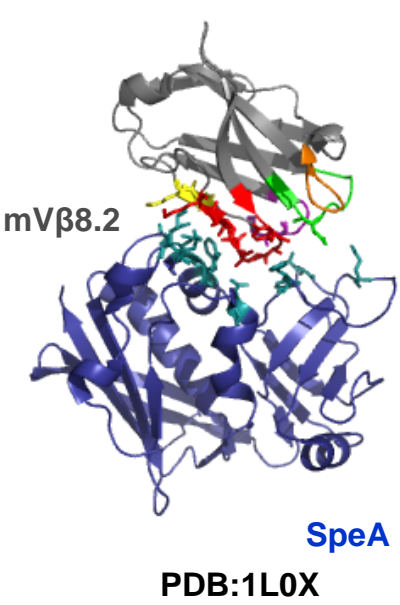

In contrast, SpeC interacts with human V $\beta 2.1$ (hV $\beta 2.1$ ) with more extensive use of the V $\beta$ region, engaging all of the hypervariable loops. The specificity of the SpeC:hV $\beta 2.1$ interaction is increased by numerous H-bonds and van der Waals interactions with both main chain and side chain atoms of hVB2.1. Non-canonical amino acid insertions in CDR1 and CDR2, and the presence of an extended CDR3 loop (at least in some $\beta$-chains), also increase the specificity of $h V \beta 2.1$ for SpeC [41].

Human V $\beta 2.1$ is also the highly restricted target of TSST-1. Thus, both SpeC and TSST- 1 interact with $\mathrm{hV} \beta 2.1$ and both engage residues in CDR2 to make contacts with V $\beta$. Although the two toxins engage a few common residues in CDR2, each also uses other distinct, non-overlapping regions for 
binding and for achieving specificity. TSST-1 uniquely binds FR3 while SpeC engages with V $\beta$ in a distinct mode by making extensive contacts involving residues from CDR1, HV4, FR2, FR3 and CDR3 in V $\beta$ [41,42]. The specificity of TSST-1 for $h V \beta 2.1$ has been attributed to the involvement of hVB2.1 FR3 residues E61 and K62. It has been speculated that TSST-1 does not activate T-cells bearing other $\mathrm{V} \beta$ domains because $75 \%$ of all other human TCR V $\beta$ regions possess a proline at position 61, resulting in reduced conformational flexibility; this reduced flexibility could prevent the specific conformation required for interaction with TSST-1. In addition, the absence of a residue at position 62 in $50 \%$ of human TCR V $\beta$ domains also contributes to the high specificity of TSST-1 for hV $\beta 2.1$ [42]. Finally, the residues that TSST-1 uses to interact with V $\beta 2.1$ share little homology with residues that other SAgs (including $\mathrm{SpeC}$ ) interact with their cognate V $\beta$ ligand (Figure 1), which further enhances TSST-1 specificity towards hV $\beta 2.1$. Recently, the molecular basis of the extreme V $\beta$ specificity of TSST-1 was determined to be the combination of both the non-canonical conformation adopted by CDR2 region of the V $\beta$ along with residues Y56 and K62 on FR3 region [74].

\section{Structural Basis of High-Affinity and Specificity of the Vß:SAg Interactions}

Although CDR2 regions have served as the predominant site for improving the affinities of V $\beta$ domains for binding to their SAgs, it is clear that other regions can also serve to enhance affinity through structural changes in each V $\beta$ :SAg interface. The involvement of regions other than CDR2, also can contribute to the high level of specificity in $\mathrm{V} \beta$ :SAg interactions exhibited by the high-affinity $\mathrm{V} \beta$ mutants. Several structures have been solved of SAgs in complex with engineered, high affinity V $\beta$ domains, thereby providing an understanding of the interactions that confer both higher affinity and specificity [42,56,58]. Not surprisingly, multiple factors, including increases in van der Waals interactions, hydrogen bonds, hydrophobic interactions, cooperativity, and conformational flexibility have all been shown to be involved. Here we discuss the generation and structural basis of high affinity for select V $\beta$ domains, which have been engineered over the past decade.

In order to generate a high affinity $\mathrm{V} \beta$ mutant for binding SEC3, mV $\beta 8.2$ was displayed on the surface of yeast and mutations were introduced by error-prone PCR, followed by site directed mutagenesis to combine mutations. One resulting mutant, called L2CM ( $\mathrm{K}_{\mathrm{D}}=7 \mathrm{nM}$ ) (also called mL2.1/A52V, a first generation variant of L3, Table 1) exhibited $\sim 450$ fold increase in affinity compared to the wild type [28]. The structural basis of the SEC3:V $\beta$ interaction has been studied extensively by alanine scan mutagenesis [76], and the high-affinity interaction with L2CM has been examined for binding energetics [77] and crystallization of various L2CM variants [58]. Although L2CM contained nine mutations, only four (A52V, S54N, K66E, Q72H) were energetically significant [77]. Structural analysis [58] indicated that the A52V mutation in CDR2, allowed an increase in hydrophobic contact area and also induced conformational changes in Q72 of the V $\beta$. The S54N mutation in CDR2 participated in affinity maturation by allowing recruitment of water molecules to SEC3:V $\beta$ interface hence mediating contacts between N26 $6^{\mathrm{V} \beta}$ and N24 ${ }^{\mathrm{V} \beta}$ with D204, K205 and F206 in SEC3. Residue K66 appeared to be conformationally restrained in the SEC3:wtV $\beta 8.2$ structure, but it adopted a more extended conformation when mutated to glutamate. This also resulted in loss of van der Waals interactions with SEC3 and unfavorable change in enthalpy of binding but a highly favorable entropic change, resulting in a higher affinity complex [77]. Mutations Q72H and A52V were shown to be involved in inducing subtle conformational changes in hypervariable loops, thereby 
affecting how CDR1 residues, and CDR2 residue 52, interacted with SEC3. Although the A52V mutation had a dominant effect in affinity maturation by mediating restructuring events of the hypervariable loops, Q72H had a minor but significant contribution to affinity maturation [58]. Recently, L2CM was further engineered by incorporating additional mutations in CDR1, HV4 and framework regions to obtain mutant $\mathrm{L} 3\left(\mathrm{~K}_{\mathrm{D}}=3 \mathrm{nM}\right)$ (Table 1 and [36]).

Similarly, mV $\beta 8.2$ was engineered for binding to SEB with a remarkable 3-million fold increase in affinity relative to wild-type $\mathrm{mV} \beta 8.2$ (Table 1 and [33]). The engineered protein (G5-8) was crystallized in complex with SEB [56]. The structural details of this complex indicated that lengthening CDR1 loop by incorporation of a serine residue at CDR1 residue 27a, and incorporation of additional mutations $\mathrm{N} 28 \mathrm{Y}$ and $\mathrm{H} 29 \mathrm{~F}$, resulted in a distinct conformation of CDR1 loop. These mutations resulted in an increase in intermolecular contacts with SEB. Y28 in G5-8 was involved in pi stacking interaction with R110 in SEB and in H-bond interaction with N60. Additionally, two mutations (A52I and G53R) acquired in CDR2, resulted in replacement of residues with smaller side chains to relatively larger side chains which resulted in an increase in van der Waals contacts and H-bond formation with N31, N60 and N88 in SEB. Overall, it was concluded that an increase in the number of intermolecular contacts between G5-8 and SEB resulted in the significant increase in binding affinity [56].

Subsequently, mVß8.2 was engineered for high affinity $\left(K_{D}=270 \mathrm{pM}\right)$ for SpeA, using yeast display [35]. Key mutations, which were responsible for affinity maturation, were acquired in CDR2 (G53K, S54H), CDR1 (N30K) and in HV4 (Q72R). The resulting mutant, KKR showed a 22,000 fold affinity improvement compared to wt $\mathrm{V} \beta 8.2\left(\mathrm{~K}_{\mathrm{D}}=6 \mu \mathrm{M}\right)$ [41]. Although there is no crystal structure of SpeA with the high affinity $\mathrm{V} \beta$, the authors used revertant mutants and energy minimized computer modeling of the mutated $\mathrm{V} \beta$-SpeA complex to propose the basis of this affinity maturation. The analysis revealed that the side chain of arginine acquired at position 53 in mutant KKR could be accommodated in a binding pocket in SpeA and promoted favorable interactions with side chain oxygen of Y90 and E88 of SpeA. Not only could this account for the affinity maturation, it could contribute to a lack of cross reactivity with SEC3, and the ability of mutant KKR to cross-react with SEB with high-affinity.

The mutant of hV $\beta 2.1$ called D10 was engineered for high affinity $\left(\mathrm{K}_{\mathrm{D}}=180 \mathrm{pM}\right)$ against TSST-1, using yeast display (Table 1 and [34]). D10 contained 14 mutations relative to stabilized wt V $\beta 2.1$ (EP-8). Of these 14 mutations, four were found to be energetically significant: three mutations in CDR2 (at residues 51, 52a and 53) and one mutation in FR3 (at residue 61). Surprisingly, positive cooperativity was observed between the distant mutations in CDR2 and FR3 [75]. Crystal structure analysis indicated that changes in intermolecular contacts, buried surface and/or shape complementarity were not the primary driving factor in affinity maturation of hV $\beta 2.1$ to TSST-1. Instead, altered conformational flexibility of D10 was proposed to have resulted in affinity increase by linking CDR2 and FR3 at the V $\beta$ :SAg interface [42]. Using a similar approach, the $\mathrm{hV} \beta 2.1$ region gene has also been engineered for high-affinity binding to SpeC (manuscript in preparation).

Finally, the $\mathrm{hV} \beta 22$ region was engineered recently for high affinity binding $\left(\mathrm{K}_{\mathrm{D}}=4 \mathrm{nM}\right)$ to SEA using yeast display [37]. The engineered mutant called FL contained ten mutations, of which five were located in CDR2. In the absence of a crystal structure of SEA with cognate V $\beta$, the authors suggested that the structural basis of high affinity may be improved electrostatic interactions (due to mutations 
N52E and E53D in CDR2), and pi stacking interactions involving N51Y in CDR2 with Y94 and Y205 in SEA's putative TCR binding site.

\section{High-Affinity Vß Domains as Neutralizing Agents}

The first study to validate the use of soluble, high-affinity $\mathrm{V} \beta$ domains in the neutralization of SAg activity was performed with the V $\beta$ L2CM against the SAg SEC3. This work showed that soluble L2CM, but not soluble wild-type V $\beta 8$, was able to completely inhibit SEC3-mediated T cell cytolysis at nanomolar concentrations [28]. This same high-affinity $\mathrm{V} \beta$ was fused to a class II MHC molecule in an attempt to increase the avidity of the interaction with SEC3 [78]. Although the fusion was shown to inhibit SEC3 activity in vitro, this study did not show whether the fusion had greater activity than the high-affinity V $\beta$ alone.

Subsequent studies showed that the high-affinity V $\beta$ against SEB, G5-8, but not the wild-type Vß8.2, was able to inhibit both in vitro and in vivo activities of SEB [33]. In this study, the in vitro activity was shown to be progressively improved in comparing different generations of mutants, with $\mathrm{K}_{\mathrm{D}}$ values from $100 \mu \mathrm{M}$ to $50 \mathrm{pM}$. For example, the $50 \mathrm{pM}$ G5-8 protein was more effective at inhibition (i.e., had a lower $\mathrm{IC}_{50}$ ) than the 650 pM G2-5 protein. Furthermore, the G5-8 protein was given to rabbits intravenously at the same time or after SEB administration, in an LPS-enhancement model of lethality, and the protein was able to prevent death even at concentrations close to stoichiometric with the SEB. In the same study, G5-8 administered daily to rabbits implanted with pumps containing SEB was able to prevent temperature increases and lethality due to the SAg. In a rabbit model of skin disease, G5-8 was able to inhibit the hypersensitivity reactions caused by SEB [38].

An in-frame fusion of the high-affinity G5-8 against SEB and the high-affinity D10 against TSST-1 yielded a single $30 \mathrm{kDa}$ protein, expressed in E. coli, was able to completely inhibit the in vitro activity of both SEB and TSST-1 [79], raising the possibility that multiple SAgs might be neutralized with a single therapeutic. An alternative approach is to identify a high-affinity V $\beta$ domain that cross-reacts with multiple SAgs. While this has not been possible for structurally distinct SAgs (e.g., SEB and TSST-1), it has been shown that V $\beta$ domains against SEB (e.g., G5-8) cross-reacted with high-affinity against SpeA, and that V $\beta$ domains were capable of inhibiting both SEB and SpeA in the LPS enhancement models [35]. More recent findings showed that it is possible to engineer a cross-reactive neutralizing V $\beta$ (L3) against both SEC3 and SEB [36].

The greatest clinical potential of soluble, high-affinity $\mathrm{V} \beta$ domains, aside from possible applications in biodefense, would be in serious diseases caused by $S$. aureus. The first study to show that high-affinity $\mathrm{V} \beta$ proteins were effective in diseases caused by S. aureus (i.e., rather than the purified toxins), involved a rabbit model of pneumonia [20]. Rabbits receiving an intrabronchial inoculation $\left(2 \times 10^{9}\right.$ cells) of $S$. aureus USA400 strain CA-MRSA c99-529 (SEB $\left.{ }^{+}\right)$were protected from death when treated with $100 \mu \mathrm{g}$ of G5-8, administered intravenously on a daily basis. Subsequent studies have shown that the high-affinity V $\beta$ L3 against SEC3 also protected rabbits exposed to an SEC-positive strain of MRSA (USA400 MW2) in the pneumonia model [36]. Interestingly, the same L3 protein was capable of significantly reducing the bacterial burden of the MRSA (USA400 MW2) strain in an infective endocarditis model [36]. These pre-clinical studies suggest that these small V $\beta$ proteins could be used intravenously, with antibiotics, to manage staphylococcal diseases that involve SAgs. The diversity of SAgs among different strains of $S$. aureus will likely require that diagnostics be 
developed for detection of the specific SAgs in patients, or that a multi-targeted therapeutic that can neutralize many of the SAgs be developed.

\section{Acknowledgements}

We thank past and present members of the Kranz lab for helpful discussions. This work was supported by various National Institutes of Health grants over the past decade, including R43 AI102432 (to David M. Kranz) and a grant from the National Institutes of Health-supported Great Lakes Regional Center for Excellence in Biodefense and Emerging Diseases (U54 AI57153 to David M. Kranz).

\section{Conflicts of Interest}

David M. Kranz co-founded a company called ImmuVen that has acquired rights from the University of Illinois for some of the T cell receptors engineered in his lab.

\section{References}

1. Marrack, P.; Kappler, J. The staphylococcal enterotoxins and their relatives. Science 1990, 248, 705-711.

2. Spaulding, A.R.; Salgado-Pabón, W; Kohler, P.L.; Horswill, A.R.; Leung, D.Y.; Schlievert, P.M. Staphylococcal and streptococcal superantigen exotoxins. Clin. Microbiol. Rev. 2013, 26, $422-447$.

3. Krakauer, T.; Stiles, B.G. The staphylococcal enterotoxin (SE) family: SEB and siblings. Virulence 2013, 4, 759-773.

4. Dinges, M.M.; Orwin, P.M.; Schlievert, P.M. Exotoxins of Staphylococcus aureus. Clin. Microbiol. Rev. 2000, 13, 16-34.

5. McCormick, J.K.; Yarwood, J.M.; Schlievert, P.M. Toxic shock syndrome and bacterial superantigens: An update. Ann. Rev. Microbiol. 2001, 55, 77-104.

6. Li, H.; Llera, A.; Malchiodi, E. L.; Mariuzza, R. A. The structural basis of T cell activation by superantigens. Ann. Rev. Immunol. 1999, 17, 435-466.

7. Baker, M.D.; Acharya, K.R. Superantigens: Structure-function relationships. Int. J. Med. Microbiol. 2004, 293, 529-537.

8. Papageorgiou, A.C.; Acharya, K.R. Microbial superantigens: From structure to function. Trends Microbiol. 2000, 8, 369-375.

9. Fraser, J.D.; Proft, T. The bacterial superantigen and superantigen-like proteins. Immunol. Rev. 2008, 225, 226-243.

10. Pless, D.D.; Ruthel, G.; Reinke, E.K.; Ulrich, R.G.; Bavari, S. Persistence of zinc-binding bacterial superantigens at the surface of antigen-presenting cells contributes to the extreme potency of these superantigens as T-cell activators. Infect. Immun. 2005, 73, 5358-5366.

11. Bavari, S.; Ulrich, R.G.; LeClaire, R.D. Cross-reactive antibodies prevent the lethal effects of Staphylococcus aureus superantigens. J. Infect. Dis. 1999, 180, 1365-1369.

12. Varshney, A.K.; Mediavilla, J.R.; Robiou, N.; Guh, A.; Wang, X.; Gialanella, P.; Levi, M.H.; Kreiswirth, B.N.; Fries, B.C. Diverse enterotoxin gene profiles among clonal complexes of Staphylococcus aureus isolates from the Bronx, New York. Appl. Environ. Microbiol. 2009, 75, 6839-6849. 
13. Hu, D.L.; Omoe, K.; Inoue, F.; Kasai, T.; Yasujima, M.; Shinagawa, K.; Nakane, A. Comparative prevalence of superantigenic toxin genes in meticillin-resistant and meticillin-susceptible Staphylococcus aureus isolates. J. Med. Microbiol. 2008, 57, 1106-1112.

14. Lindsay, J.A.; Ruzin, A.; Ross, H.F.; Kurepina, N.; Novick, R.P. The gene for toxic shock toxin is carried by a family of mobile pathogenicity islands in Staphylococcus aureus. Mol. Microbiol. 1998 29, 527-543.

15. Novick, R.P.; Schlievert, P.; Ruzin, A. Pathogenicity and resistance islands of staphylococci. Microbes Infect. 2001, 3, 585-594.

16. Fitzgerald, J.R.; Monday, S.R.; Foster, T.J.; Bohach, G.A.; Hartigan, P.J.; Meaney, W.J.; Smyth, C.J. Characterization of a putative pathogenicity island from bovine Staphylococcus aureus encoding multiple superantigens. J. Bacteriol. 2001, 183, 63-70.

17. Betley, M.J.; Mekalanos, J.J. Staphylococcal enterotoxin A is encoded by phage. Science 1985, 229, 185-187.

18. Derzelle, S.; Dilasser, F.; Duquenne, M.; Deperrois, V. Differential temporal expression of the staphylococcal enterotoxins genes during cell growth. Food Microbiol. 2009, 26, 896-904.

19. Bachert, C.; Gevaert, P.; Zhang, N.; van Zele, T.; Perez-Novo, C. Role of staphylococcal superantigens in airway disease. Chem. Immunol. Allergy 2007, 93, 214-236.

20. Strandberg, K.L.; Rotschafer, J.H.; Vetter, S.M.; Buonpane, R.A.; Kranz, D.M.; Schlievert, P.M. Staphylococcal superantigens cause lethal pulmonary disease in rabbits. J. Infect. Dis. 2010, 202, 1690-1697.

21. Schlievert, P.M.; Case, L.C.; Strandberg, K.L.; Abrams, B.B.; Leung, D.Y. Superantigen profile of Staphylococcus aureus isolates from patients with steroid-resistant atopic dermatitis. Clin. Infect. Dis. 2008, 46, 1562-1567.

22. Macias, E.S.; Pereira, F.A.; Rietkerk, W.; Safai, B. Superantigens in dermatology. J. Am. Acad. Dermatol. 2011, 64, 455-472; quiz 473-454.

23. Bohach, G.A.; Fast, D.J.; Nelson, R.D.; Schlievert, P.M. Staphylococcal and streptococcal pyrogenic toxins involved in toxic shock syndrome and related illnesses. Crit. Rev. Microbiol. 1990, 17, 251-272.

24. Lappin, E.; Ferguson, A.J. Gram-positive toxic shock syndromes. Lancet Infect. Dis. 2009, 9, 281-290.

25. Dhodapkar, K.; Corbacioglu, S.; Chang, M.W.; Karpatkin, M.; DiMichele, D. Purpura fulminans caused by group A beta-hemolytic Streptococcus sepsis. J. Pediatr. 2000, 137, 562-567.

26. Tilahun, A.Y.; Holz, M.; Wu, T.T.; David, C.S.; Rajagopalan, G. Interferon gamma-dependent intestinal pathology contributes to the lethality in bacterial superantigen-induced toxic shock syndrome. PLOS ONE 2011, 6, doi: 10.1371/journal.pone.0016764.

27. Tilahun, A.Y.; Karau, M.J.; Clark, C.R.; Patel, R.; Rajagopalan, G. The impact of tacrolimus on the immunopathogenesis of staphylococcal enterotoxin-induced systemic inflammatory response syndrome and pneumonia. Microbes Infect. 2012, 14, 528-536.

28. Kieke, M.C.; Sundberg, E.; Shusta, E.V.; Mariuzza, R.A.; Wittrup, K.D.; Kranz, D.M. High affinity $\mathrm{T}$ cell receptors from yeast display libraries block $\mathrm{T}$ cell activation by superantigens. J. Mol. Biol. 2001, 307, 1305-1315. 
29. Garrison, L.; McDonnell, N. Etanercept: therapeutic use in patients with rheumatoid arthritis. Ann. Rheum. Dis. 1999, 58, 165-169.

30. Combe, B. Update on the use of etanercept across a spectrum of rheumatoid disorders. Biologics 2008, 2, 165-173.

31. Boder, E.T.; Wittrup, K.D. Yeast surface display for directed evolution of protein expression, affinity, and stability. Meth. Enzymol. 2000, 328, 430-444.

32. Boder, E.T.; Wittrup, K.D. Yeast surface display for screening combinatorial polypeptide libraries. Nat. Biotechnol. 1997, 15, 553-557.

33. Buonpane, R.A.; Churchill, H.R.; Moza, B.; Sundberg, E.J.; Peterson, M.L.; Schlievert, P.M.; Kranz, D.M. Neutralization of staphylococcal enterotoxin B by soluble, high-affinity receptor antagonists. Nat. Med. 2007, 13, 725-729.

34. Buonpane, R.A.; Moza, B.; Sundberg, E.J.; Kranz, D.M. Characterization of T cell receptors engineered for high affinity against toxic shock syndrome toxin-1. J. Mol. Biol. 2005, 353, 308-321.

35. Wang, N.; Mattis, D.M.; Sundberg, E.J.; Schlievert, P.M.; Kranz, D.M. A single, engineered protein therapeutic agent neutralizes exotoxins from both Staphylococcus aureus and Streptococcus pyogenes. Clin. Vaccine Immunol. 2010, 17, 1781-1789.

36. Mattis, D.M.; Spaulding, A.R.; Chuang-Smith, O.N.; Sundberg, E.J.; Schlievert, P.M.; Kranz, D.M. Engineering a soluble high-affinity receptor domain that neutralizes staphylococcal enterotoxin C in rabbit models of disease. Protein Eng. Des. Sel. 2013, 26, 133-142.

37. Sharma, P.; Postel, S.; Sundberg, E.J.; Kranz, D.M. Characterization of the Staphylococcal enterotoxin $A$ : V $\beta$ receptor interaction using human receptor fragments engineered for high affinity. Protein Eng. Des. Sel. 2013, 26, 781-789.

38. John, C.C.; Niermann, M.; Sharon, B.; Peterson, M.L.; Kranz, D.M.; Schlievert, P.M. Staphylococcal toxic shock syndrome erythroderma is associated with superantigenicity and hypersensitivity. Clin. Infect. Dis. 2009, 49, 1893-1896.

39. Li, H.; Llera, A.; Tsuchiya, D.; Leder, L.; Ysern, X.; Schlievert, P.M.; Karjalainen, K.; Mariuzza, R.A. Three-dimensional structure of the complex between a $\mathrm{T}$ cell receptor beta chain and the superantigen staphylococcal enterotoxin B. Immunity 1998, 9, 807-816.

40. Fields, B.A.; Malchiodi, E.L.; Li, H.; Ysern, X.; Stauffacher, C.V.; Schlievert, P.M.; Karjalainen, K.; Mariuzza, R.A. Crystal structure of a T-cell receptor b-chain complexed with a superantigen. Nature 1996, 384, 188-192.

41. Sundberg, E.J.; Li, H.; Llera, A.S.; McCormick, J.K.; Tormo, J.; Schlievert, P.M.; Karjalainen, K.; Mariuzza, R.A. Structures of two streptococcal superantigens bound to TCR beta chains reveal diversity in the architecture of T cell signaling complexes. Structure 2002, 10, 687-699.

42. Moza, B.; Varma, A.K.; Buonpane, R.A.; Zhu, P.; Herfst, C.A.; Nicholson, M.J.; Wilbuer, A.K.; Seth, N.P.; Wucherpfennig, K.W.; McCormick, J.K.; et al. Structural basis of T-cell specificity and activation by the bacterial superantigen TSST-1. EMBO J. 2007, 26, 1187-1197.

43. Petersson, K.; Thunnissen, M.; Forsberg, G.; Walse, B. Crystal structure of a sea variant in complex with MHC class II reveals the ability of Sea to crosslink MHC molecules. Structure 2002, 10, 1619-1626. 
44. Jardetzky, T.S.; Brown, J.H.; Gorga, J.C.; Stern, L.J.; Urban, R.G.; Chi, Y.; Stauffacher, C.; Strominger, J.; Wiley, D.C. Three-dimensional structure of a human class II histocompatibility molecule complexed with superantigen. Nature 1994, 368, 711-718.

45. Sundberg, E.J.; Andersen, P.S.; Schlievert, P.M.; Karjalainen, K.; Mariuzza, R.A. Structural, energetic, and functional analysis of a protein-protein interface at distinct stages of affinity maturation. Structure 2003, 11, 1151-1161.

46. Papageorgiou, A.C.; Collins, C.M.; Gutman, D.M.; Kline, J.B.; O’Brien, S.M.; Tranter, H.S.; Acharya, K.R. Structural basis for the recognition of superantigen streptococcal pyrogenic exotoxin A (SpeA1) by MHC class II molecules and T-cell receptors. EMBO J. 1999, 18, 9-21.

47. Li, Y.; Li, H.; Dimasi, N.; McCormick, J.K.; Martin, R.; Schuck, P.; Schlievert, P.M.; Mariuzza, R.A. Crystal structure of a superantigen bound to the high-affinity, zinc- dependent site on MHC class II. Immunity 2001, 14, 93-104.

48. Wang, X.; Xu, M.; Cai, Y.; Yang, H.; Zhang, H.; Zhang, C. Functional analysis of the disulphide loop mutant of staphylococcal enterotoxin C2. Appl. Microbiol. Biotechnol. 2009, 82, 861-871.

49. Hovde, C.J.; Marr, J.C.; Hoffmann, M.L.; Hackett, S.P.; Chi, Y.I.; Crum, K.K.; Stevens, D.L.; Stauffacher, C.V.; Bohach, G.A. Investigation of the role of the disulphide bond in the activity and structure of staphylococcal enterotoxin C1. Mol. Microbiol. 1994 13, 897-909.

50. Schlievert, P.M.; Jablonski, L.M.; Roggiani, M.; Sadler, I.; Callantine, S.; Mitchell, D.T.; Ohlendorf, D.H.; Bohach, G.A. Pyrogenic toxin superantigen site specificity in toxic shock syndrome and food poisoning in animals. Infect. Immun. 2000, 68, 3630-3634.

51. Kim, J.; Urban, R.G.; Strominger, J.L.; Wiley, D.C. Toxic shock syndrome toxin-1 complexed with a class II major histocompatibility molecule HLA-DR1. Science 1994, 266, 1870-1874.

52. Tiedemann, R.E.; Urban, R.J.; Strominger, J.L.; Fraser, J.D. Isolation of HLA-DR1.(staphylococcal enterotoxin A)2 trimers in solution. Proc. Natl. Acad. Sci. USA 1995, 92, 12156-12159.

53. Schad, E.M.; Zaitseva, I.; Zaitsev, V.N.; Dohlsten, M.; Kalland, T.; Schlievert, P.M.; Ohlendorf, D.H.; Svensson, L.A. Crystal structure of the superantigen staphylococcal enterotoxin type A. EMBO J. 1995, 14, 3292-3301.

54. Sundstrom, M.; Hallen, D.; Svensson, A.; Schad, E.; Dohlsten, M.; Abrahmsen, L. The Co-crystal structure of staphylococcal enterotoxin type A with $\mathrm{Zn}^{2+}$ at $2.7 \mathrm{~A}$ resolution. Implications for major histocompatibility complex class II binding. J. Biol. Chem. 1996, 271, 32212-32216.

55. Papageorgiou, A.C.; Tranter, H.S.; Acharya, K.R. Crystal structure of microbial superantigen staphylococcal enterotoxin B at 1.5 A resolution: implications for superantigen recognition by MHC class II molecules and T-cell receptors. J. Mol. Biol. 1998, 277, 61-79.

56. Bonsor, D.A.; Postel, S.; Pierce, B.G.; Wang, N.; Zhu, P.; Buonpane, R.A.; Weng, Z.; Kranz, D.M.; Sundberg, E.J. Molecular basis of a million-fold affinity maturation process in a protein-protein interaction. J. Mol. Biol. 2011, 411, 321-328.

57. Chi, Y.I.; Sadler I.; Jablonski, L.M.; Callantine, S.D.; Deobald, C.F.; Stauffacher, C.V.; Bohach, G.A. Zinc-mediated dimerization and its effect on activity and conformation of staphylococcal enterotoxin type C. J. Biol. Chem. 2002, 277, 22839-22846.

58. Cho, S.; Swaminathan, C.P.; Yang, J.; Kerzic, M.C.; Guan, R.; Kieke, M.C.; Kranz, D.M.; Mariuzza, R.A.; Sundberg, E.J. Structural basis of affinity maturation and intramolecular cooperativity in a protein-protein interaction. Structure 2005, 13, 1775-1787. 
59. Papageorgiou, A.C.; Brehm, R.D.; Leonidas, D.D.; Tranter, H.S.; Acharya, K.R. The refined crystal structure of toxic shock syndrome toxin-1 at 2.07 A resolution. J. Mol. Biol. 1996, 260, 553-569.

60. Earhart, C.A.; Vath, G.M.; Roggiani, M.; Schlievert, P.M.; Ohlendorf, D.H. Structure of streptococcal pyrogenic exotoxin A reveals a novel metal cluster. Protein Sci. 2000, 9, 1847-1851.

61. Roussel, A.; Anderson, B.F.; Baker, H.M.; Fraser, J.D.; Baker, E.N. Crystal structure of the streptococcal superantigen SPE-C: Dimerization and zinc binding suggest a novel mode of interaction with MHC class II molecules. Nat. Struct. Biol. 1997, 4, 635-643.

62. Saline, M.; Rödström, K.E.; Fischer, G.; Orekhov, V.Y.; Karlsson, B.G.; Lindkvist-Petersson, K. The structure of superantigen complexed with TCR and MHC reveals novel insights into superantigenic T cell activation. Nat. Commun. 2010, 1, doi:10.1038/ncomms1117.

63. Petersson, K.; Pettersson, H.; Skartved, N.J.; Walse, B.; Forsberg, G. Staphylococcal enterotoxin $\mathrm{H}$ induces $\mathrm{V}$ alpha-specific expansion of T cells. J. Immunol. 2003, 170, 4148-4154.

64. Kappler, J.; Kotzin, B.; Herron, L.; Gelfand, E.W.; Bigler, R.D.; Boylston, A.; Carrel, S.; Posnett, D.N.; Choi, Y.; Marrack, P. V beta-specific stimulation of human $\mathrm{T}$ cells by staphylococcal toxins. Science 1989, 244, 811-813.

65. Thomas, D.; Dauwalder, O.; Brun, V.; Badiou, C.; Ferry, T.; Etienne, J.; Vandenesch, F.; Lina, G. Staphylococcus aureus superantigens elicit redundant and extensive human Vbeta patterns. Infect. Immun. 2009, 77, 2043-2050.

66. Malchiodi, E.L.; Eisenstein, E.; Fields, B.A.; Ohlendorf, D.H.; Schlievert, P.M.; Karjalainen, K.; Mariuzza, R.A. Superantigen binding to a $\mathrm{T}$ cell receptor b chain of known three-dimensional structure. J. Exp. Med. 1995, 182, 1833-1845.

67. Khandekar, S.S.; Bettencourt, B.M.; Wyss, D.F.; Naylor, J.W.; Brauer, P.P.; Huestis, K.; Dwyer, D.S.; Profy, A.T.; Osburne, M.S.; Banerji, J.; et al. Conformational integrity and ligand binding properties of a single chain T-cell receptor expressed in Escherichia coli. J. Biol. Chem. 1997, 272, 32190-32197.

68. Andersen, P.S.; Geisler, C.; Buus, S.; Mariuzza, R.A.; Karjalainen, K. Role of TCR-ligand affinity in T cell activation by bacterial superantigens. J. Biol. Chem. 2001, 276, 33452-33457.

69. Wang, N.; Kranz, D.M. University of Illinois, Urbana, IL, USA, Unpublished work, 2013.

70. Kieke, M.C.; Shusta, E.V.; Boder, E. T.; Teyton, L.; Wittrup, K.D.; Kranz, D.M. Selection of functional T cell receptor mutants from a yeast surface- display library. Proc. Natl. Acad. Sci. USA 1999, 96, 5651-5656.

71. Richman, S.A.; Aggen, D.H.; Dossett, M.L.; Donermeyer, D.L.; Allen, P.M.; Greenberg, P.D.; Kranz, D.M. Structural features of T cell receptor variable regions that enhance domain stability and enable expression as single-chain ValphaVbeta fragments. Mol. Immunol. 2009, 46, 902-916.

72. Shusta, E.V.; Kieke, M.C.; Parke, E.; Kranz, D.M.; Wittrup, K.D. Yeast polypeptide fusion surface display levels predict thermal stability and soluble secretion efficiency. J. Mol. Biol. 1999, 292, 949-956.

73. Sundberg, E.J.; Deng, L.; Mariuzza, R.A. TCR recognition of peptide/MHC class II complexes and superantigens. Semin. Immunol. 2007, 19, 262-271. 
74. Nur-ur Rahman, A.K.; Bonsor, D.A.; Herfst, C.A.; Pollard, F.; Peirce, M.; Wyatt, A.W.; Kasper, K.J.; Madrenas, J.; Sundberg, E.J.; McCormick, J.K. The T cell receptor beta-chain second complementarity determining region loop (CDR2beta) governs T cell activation and Vbeta specificity by bacterial superantigens. J. Biol. Chem. 2011, 286, 4871-4881.

75. Moza, B.; Buonpane, R.A.; Zhu, P.; Herfst, C.A.; Rahman, A.K.; McCormick, J.K.; Kranz, D.M.; Sundberg, E.J. Long-range cooperative binding effects in a T cell receptor variable domain. Proc. Natl. Acad. Sci. USA 2006, 103, 9867-9872.

76. Churchill, H.R.; Andersen, P.S.; Parke, E.A.; Mariuzza, R.A.; Kranz, D.M. Mapping the energy of superantigen Staphylococcus enterotoxin C3 recognition of an alpha/beta T cell receptor using alanine scanning mutagenesis. J. Exp. Med. 2000, 191, 835-846.

77. Yang, J.; Swaminathan, C.P.; Huang, Y.; Guan, R.; Cho, S.; Kieke, M.C.; Kranz, D.M.; Mariuzza, R.A.; Sundberg, E.J. Dissecting cooperative and additive binding energetics in the affinity maturation pathway of a protein-protein interface. J. Biol. Chem. 2003, 278, 50412-50421.

78. Hong-Geller, E.; Mollhoff, M.; Shiflett, P.R.; Gupta, G. Design of chimeric receptor mimics with different TcRVbeta isoforms. Type-specific inhibition of superantigen pathogenesis. J. Biol. Chem. 2004, 279, 5676-5684.

79. Yang, X.; Buonpane, R.A.; Moza, B.; Rahman, A.K.; Wang, N.; Schlievert, P.M.; McCormick, J.K.; Sundberg, E.J.; Kranz, D.M. Neutralization of multiple staphylococcal superantigens by a single-chain protein consisting of affinity-matured, variable domain repeats. J. Infect. Dis. 2008, 198, 344-348.

(C) 2014 by the authors; licensee MDPI, Basel, Switzerland. This article is an open access article distributed under the terms and conditions of the Creative Commons Attribution license (http://creativecommons.org/licenses/by/3.0/). 